\title{
CRAMP IN CASES OF PROLAPSED INTERVERTEBRAL DISC
}

\author{
BY \\ LIONEL WOLMAN \\ From the Department of Nervous Diseases, Royal Sheffield Infirmary and Hospital
}

Although cramp has been mentioned as a symptom by several writers on the subject of prolapsed intervertebral discs (Bradford and Spurling, 1941 ; O'Connell, 1943 ; Lenhard, 1947) no study has hitherto been made of its exact nature, frequency, and relationships. It was not until the routine follow-up of cases of sciatica, which had been treated surgically, was begun that it was noticed that the symptom of painful cramps in the leg was fairly common in postoperative cases. This served to focus attention on the symptom, and an inquiry about it was therefore made in all cases, both before and after operation. The purpose of this paper is to record these observations, and if possible to relate the symptom to conditions found at, or produced by, the operation, and to discuss the symptom in relation to theories now held on the atiology of muscle cramp.

\section{Material}

The observations recorded here were made in the Department of Nervous Diseases, Royal Sheffield Infirmary and Hospital, in a series of 204 cases of backache and sciatica which were thought to be due to herniation of an intervertebral disc and were subjected to operation. The patients were operated on between the years 1939 and 1946 by Mr. James Hardman, and a routine follow-up examination was carried out in 1947, -at least twelve months and up to seven years after operation. The figures given below are extracted from the complete follow-up survey carried out by the writer, the results of which will be published in a later paper.

Type of Operation.-The operation performed was either a laminectomy or a hemilaminectomy, with exploration of the disc spaces between the fourth and fifth lumbar vertebræ and the lumbosacral articulation. As much prolapsed material as possible was removed, and if exploration was negative further spaces were investigated if this was thought necessary by the operating surgeon. In about two-thirds of the cases division of one or two sensory roots, either at the same segmental level as the disc or at the segment above, was made. This procedure was adopted in an attempt to be certain that pain was relieved (Walker, 1945) and to avoid further root pressure if more material should prolapse.
This procedure has since been abandoned in favour of complete curettage of the disc space. Of the 204 patients, 142 had division of one or more prsterior roots, while the remaining sixty-two had no such division. The surgeon's decision whether to section the posterior root was influenced by his estimate of the completeness of the disc removal and to a lesser extent by the severity of root pain.

Type of Cramp.-In most cases the cramp came on at night while the patient was in bed. It affected the calf alone, the thigh alone, the foot alone, or combination of these. There was always associated pain, and the patient could always feel the muscle harden or, in the case of the foot, see and feel the toes being drawn down under the sole. These symptoms were always verified before a pain in the leg was called cramp.

When there had been cramp before operation, this symptom began after the onset of sciatica and never before. The most characteristic thing about the postoperative cramps was that they were very frequent immediately after operation, occurring nightly or every other night for the first few weeks, and gradually becoming less frequent so that they occurred about weekly or monthly twelve to eighteen months after operation. With a further lapse of time they became very infrequent, occurring only once every three or four months. This infrequency made observations on actual attacks of cramp difficult. None have yet been recorded as occurring more than five years after operation.

Incidence of Cramp.-Cramps occurred as a preoperative symptom in sixteen out of the 204 cases in the series ( 8 per cent.). It occurred after operation in fifty-two cases (26 per cent.). Of these postoperative cases, in the group of sixty-two cases not having a sensory root divided, nine (15 per cent.) developed cramps, whereas, in the 142 cases having a posterior root division, forty-three (30 per cent.) developed cramps. Thus cramps appear twice as commonly in the cases having division of sensory roots as in those not having this performed. 
TABLE I

AGE AND SEX INCIDENCE OF CASES

\begin{tabular}{|c|c|c|c|c|c|c|}
\hline Series & $\begin{array}{l}\text { No. } \\
\text { in } \\
\text { series }\end{array}$ & $\begin{array}{l}\text { Average } \\
\text { age }\end{array}$ & $\begin{array}{c}\text { Age of } \\
\text { youngest }\end{array}$ & $\begin{array}{c}\text { Age } \\
\text { of } \\
\text { eldest }\end{array}$ & Men & Women \\
\hline $\begin{array}{l}\text { Pre-operative } \\
\text { cramps. } \\
\text { Postoperative }\end{array}$ & 16 & & 20 & 54 & 15 & 1 \\
\hline $\begin{array}{l}\text { cramps } \\
\text { Cases }\end{array}$ & 52 & 36 & 17 & 50 & 43 & 9 \\
\hline cramp $\ldots \quad \ldots$ & 136 & 36 & 17 & 68 & 112 & 24 \\
\hline Whole series & 204 & 36 & 17 & 68 & 170 & 34 \\
\hline
\end{tabular}

Of the sixteen patients complaining of cramp before operation, ten were relieved of this symptom after operation, while in the remaining six the cramps were more frequent and severe afterwards in all but one, whose cramps persisted at about the same frequency and intensity. It has been mentioned already that the cramp in these cases tends to come on at night while the patient is in bed, thus differentiating the pain from that of intermittent claudication. A further point of difference is the age incidence, which is shown in Table $I$. It will be seen that the average age of the patients with cramp was approximately the same as in the whole series of sciatica cases; this suggests that vascular factors of a degenerative type play no part in the causation of the cramp.

Sex Incidence.-The sex of the patients with cramp is shown in Table I. Although pre-operative cramps were commoner in men than in women, the sex distribution in the group with cramp after operation was similar to that for the whole series (about five men to one woman); this suggests that sex has no part in the ætiology of these cramps.

TABLE II

PRECIPITATING FACTORS IN CRAMP

\begin{tabular}{|c|c|c|}
\hline Precipitating factor & $\begin{array}{l}\text { No. with } \\
\text { pre- } \\
\text { operative } \\
\text { cramp }\end{array}$ & $\begin{array}{l}\text { No. with } \\
\text { post- } \\
\text { operative } \\
\text { cramp }\end{array}$ \\
\hline In bed at night .. $\quad .$. & 7 & 32 \\
\hline While bending or kneeling $\ldots$ & $0^{\circ}$ & 3 \\
\hline While sitting $\quad$. & 2 & 3 \\
\hline Stretching leg $\ldots \quad$ '.. & 2 & $\mathbf{0}$ \\
\hline $\begin{array}{l}\text { While standing with weight } \\
\text { on leg.. } \quad . .\end{array}$ & 0 & 3 \\
\hline $\begin{array}{c}\text { No definite cause-cramp at } \\
\text { any time of day or night }\end{array}$ & $5^{\prime}$ & 11 \\
\hline Total & 16 & 52 \\
\hline
\end{tabular}

Precipitating Cause of Cramps.-All the patients were asked what factors brought on the cramp. $Z$ The replies (Table II) showed that nocturnal cramp occurred in more than half the cases.

Factors Relieving Cramp.-The cramp passed off spontaneously in all the patients in whom it ${ }_{0}$ occurred pre-operatively, but could be relieved by rubbing the affected part or by pressing the foot $\frac{\overline{0}}{0}$ against something firm. In the fifty-two patients in whom cramp was postoperative, changing the position of the leg was most effective and relieved $\stackrel{\vec{s}}{\rightarrow}$ cramp in fifteen cases, pressing the foot to the ground was successful in ten, and six found that 음 rubbing the affected part gave relief. Three patients $\frac{\bar{\omega}}{\neg}$ thought they could relieve cramp by taking aspirin $\odot$ before going to bed, and eight cases used a combina- in

TABLE , III

MUSCLES AFFECTED BY CRAMP

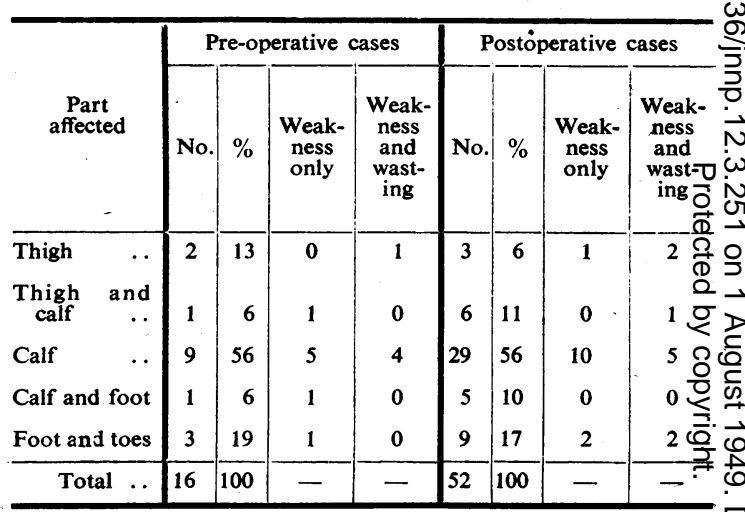

tion of all these methods to obtain relief. The remaining ten adopted no particular measures but allowed the cramp to pass off spontaneously.

Site of Cramp.-The muscles affected by cramp are indicated in Table III. As many observers have previously noted, the calf muscles are by far the commonest site for muscular cramps. In the sixteen pre-operative cases, wasting of the affected muscles was found in five patients, while in all $\overline{3}$ except three there was definite weakness of these muscles compared with the opposite side. Fibrilla- $\frac{5}{3}$ tion was seen in the calf in two patients only. In the fifty-two postoperative cases weakness and $\bigcirc$ wasting were less frequently found in the affected muscles, there being ten patients with wasting and twenty-three with weakness. As cramps were $\rightarrow$ fairly infrequent by the time of the follow-up, this observation is of doubtful significance. The dis- N tribution of the weakness and wasting is shown in Table III. 
TABLE IV

RELATIONSHIP OF CRAMP TO THE LEVEL OF THE PROLAPSED DISC

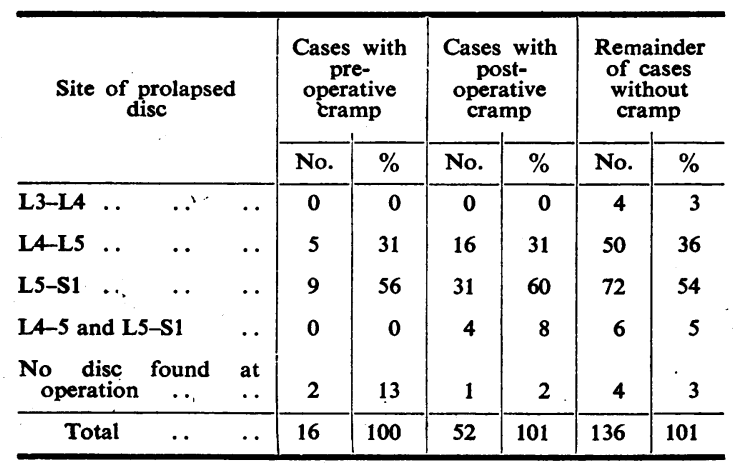

The degree of weakness and wasting of the muscles liable to develop cramp was not significantly different from that seen in cases not developing cramp either before or after operation.

Cramp and Level of Prolapsed Disc.-The relationship of cramp to the level of the prolapsed disc found at operation was also investigated. Table IV gives an analysis of the site of the prolapsed disc in the various groups. From this it will be seen that the distribution is approximately the same in all three groups, which suggests that the occurrence of cramp is independent of the level of the prolapse of the disc.

Site of Cramp and Level of Prolapsed Disc.-In Table $\mathrm{V}$ the relationship between the site of cramp and the level of prolapsed intervertebral disc is shown both for the group suffering from cramp before operation and the group with postoperative cramp.

As is to be expected from the fact that a prolapsed disc can affect the nerve root either of its own or of a higher segmental level according to its

TABLE V

RELATIONSHIP BETWEEN SITE OF CRAMP AND LEVEL OF 'PROLAPSED DISC

\begin{tabular}{|c|c|c|c|c|c|c|c|}
\hline \multirow{2}{*}{$\begin{array}{c}\text { Part } \\
\text { affected } \\
\text { by } \\
\text { cramp }\end{array}$} & \multicolumn{3}{|c|}{$\begin{array}{l}\text { Pre-operative } \\
\text { cramp }\end{array}$} & \multicolumn{3}{|c|}{$\begin{array}{l}\text { Postoperative } \\
\text { cramp }\end{array}$} & \multirow{2}{*}{$\begin{array}{c}\text { No } \\
\text { disc } \\
\text { found }\end{array}$} \\
\hline & L4-L5 & L5-S1 & $\begin{array}{c}\text { No } \\
\text { disc } \\
\text { found }\end{array}$ & L4-L5 & L5-S1 & $\begin{array}{l}\text { L4-5 } \\
\text { and } \\
\text { L5-S1 }\end{array}$ & \\
\hline Thigh .. & 1 & 1 & 0 & 3 & 0 & 0 & 0 \\
\hline $\begin{array}{l}T h \text { i } g h \\
\text { and calf }\end{array}$ & 0 & 1 & 0 & 1 & 5 & 0 & 0 \\
\hline Calf .. & 2 & 6 & 1 & 8 & 19 & 2 & 1 \\
\hline $\begin{array}{c}\text { Calf and } \\
\text { foot ... }\end{array}$ & 1 & 0 & 0 & 1 & 1 & 1 & 0 \\
\hline $\begin{array}{c}\text { Foot and } \\
\text { toes } \ldots\end{array}$ & 1 & 1 & 1 & 3 & 6 & 1 & 0 \\
\hline
\end{tabular}

medial or lateral position, there is no definite correlation between the muscle affected by cramp and the level of the prolapsed disc. The type of disc found at operation, especially as regards the position of prolapsed material, was therefore investigated next.

Relationship of Cramp to Type of Disc.-The type of disc found at operation had to be discovered from the operation notes, but in some cases no particular comments about the disc were found. It was possible to divide the cases in which special comment was made into four categories according to whether the prolapsed disc appeared as a slight medial bulge, à large central prolapse, a small lateral prolapse, or a large lateral prolapse. This

TABLE VI

RELATIONSHIP OF CRAMP TO TYPE OF DISC

\begin{tabular}{|c|c|c|c|c|c|c|}
\hline \multirow{2}{*}{$\begin{array}{c}\text { Type of } \\
\text { prolapsed } \\
\text { disc }\end{array}$} & \multicolumn{2}{|c|}{$\begin{array}{l}\text { Pre- } \\
\text { operative } \\
\text { cramps }\end{array}$} & \multicolumn{2}{|c|}{$\begin{array}{l}\text { Post- } \\
\text { operative } \\
\text { cramps }\end{array}$} & \multicolumn{2}{|c|}{$\begin{array}{l}\text { Rest of } \\
\text { series }\end{array}$} \\
\hline & No. & $\%$ & No. & $\%$ & No. & $\%$ \\
\hline $\begin{array}{cc}\text { No evidence } \\
\text { prolapse }\end{array}$ & 2 & 13 & 1 & 2 & 4 & 3 \\
\hline Slight median & & & & & & \\
\hline bulge .. $\ldots$ & 2 & 13 & 15 & 29 & 32 & 23 \\
\hline $\begin{array}{c}\text { Large central pro- } \\
\text { lapse } \ldots\end{array}$ & 3 & 19 & 21 & 41 & 56 & 41 \\
\hline Small lateral pro- & $?$ & 13 & 1 & $?$ & 12 & 0 \\
\hline Large lateral pro- & 2 & 13 & 1 & 2 & 12 &, 9 \\
\hline lapse $\ldots$. & 7 & 44 & 10 & 19 & 20 & 15 \\
\hline of disc type .. & 0 & $\mathbf{0}$ & 4 & 8 & 12 & 9 \\
\hline Total & 16 & 102 & 52 & 101 & 136 & 100 \\
\hline
\end{tabular}

is obviously an arbitrary and artificial division, as the static conditions seen at operation may not represent the true state of affairs, but it was the only method possible. In Table VI the findings are compared with those obtained in the 136 cases without cramps. The findings in the cases developing cramp after operation resemble those in the general series, but in those suffering cramp before operation there was a higher proportion with large lateral prolapsed discs. These figures suggest, therefore, that cramps are more liable to develop in cases having a large lateral prolapse of the disc. As the nerve root was often stretched over the summit of the large prolapsed discs, attention was next focused on the posterior nerve root.

Cramp and the Posterior Root Section.-It was found that most of the fifty-two patients developing postoperative cramp had one or more posterior 
nerve roots sectioned at operation. Thus, only nine patients (18 per cent.) did not have a root divided, while 83 per cent. did, 54 per cent. having division of one sensory root and 29 per cent. having two. Of the patients with cramp and without sensory root division, one had paraplegia before operation which persisted afterwards and at operation the roots of the cauda equina were found to be matted together, three had very laterally placed discs with the nerve root stretched over the summit of the disc, and the remaining five had nothing special recorded about the operation. It is worth noting that in only one patient out of the fifty-two developing cramp after operation was the cramp bilateral in both calves. This patient was the only one in whom the posterior root was divided on both sides. The patient who complained most bitterly of all about painful cramps in the calf had only a partial division of one posterior nerve root. (Table VII.)

TABLE VII

CRAMP AND POSTERIOR ROOT SECTION

\begin{tabular}{|c|c|c|c|c|c|c|}
\hline \multirow[b]{2}{*}{$\begin{array}{c}\text { Part affected by } \\
\text { cramp }\end{array}$} & \multicolumn{6}{|c|}{ Roots sectioned } \\
\hline & L4 & L5 & S1 & $\underset{5}{\mathrm{L4}}$ & $\begin{array}{l}\text { L5 } \\
\text { and } \\
\text { S1 }\end{array}$ & None \\
\hline Thigh .. & 1 & 1 & $\mathbf{0}$ & 0 & $\mathbf{0}$ & 1 \\
\hline Thigh and calf. . & 1 & 3 & 1 & $\mathbf{0}$ & $\mathbf{0}$ & 1 \\
\hline Calf $\quad$. & 3 & 11 & 2 & 3 & 3 & 7 \\
\hline Calf and foot .. & 1 & 1 & $\mathbf{0}$ & 2 & 1 & $\mathbf{0}$ \\
\hline Foot and toes .. & 0 & 3 & $\mathbf{0}$ & 3 & 3 & 0. \\
\hline Total & $\begin{array}{c}6 \\
(12 \%)\end{array}$ & $\begin{array}{c}19 \\
(36 \%)\end{array}$ & $\begin{array}{c}3 \\
(6 \%)\end{array}$ & $\begin{array}{c}8 \\
(15 \%)\end{array}$ & $\begin{array}{c}7 \\
(13 \%)\end{array}$ & $\begin{array}{c}9 \\
(18 \%)\end{array}$ \\
\hline
\end{tabular}

Site of Cramp and Posterior Root Section.-An attempt was made to correlate the muscle affected by cramp with the root divided. Although there was a tendency for the thigh muscles to be affected when the fourth lumbar root was divided and for the foot to be involved when the fifth lumbar and first sciatic roots were divided, there were exceptions, as might be expected from the fact that there is an overlap between the muscles and cord segments supplying them, each muscle being supplied by more than one segment and each segmental level supplying several muscles.

Relationship of Cramp to $X$-Ray Appearances.As muscular cramps are common in patients with arthritis of the knee, hip, or spine (Pemberton, $1935)$, the $x$-ray appearances were studied. It was found that in the pre-operative group 44 per cent. showed no abnormality of the lumbar spine on $x$-ray examination, while 38 per cent. had slight narrowing of the disc space and none showed arthritic changes. In the postoperative group 46
TABLE VIII

RELATIONSHIP OF CRAMP TO RESULT OF OPERATION ZN PATIENTS WITH CRAMP BEFORE OPERATION :

\begin{tabular}{|c|c|c|c|c|c|}
\hline \multirow{2}{*}{ Series } & \multirow{2}{*}{$\begin{array}{l}\text { Number } \\
\text { in series }\end{array}$} & \multicolumn{2}{|c|}{$\begin{array}{l}\text { Good } \\
\text { result }\end{array}$} & \multicolumn{2}{|c|}{$\begin{array}{l}\text { Badwo } \\
\text { resulf }\end{array}$} \\
\hline & & No. & $\%$ & No. & 串 \\
\hline $\begin{array}{c}\text { Cases with cramp before } \\
\text { operation }\end{array}$ & 16 & 9 & 56 & 7 & \\
\hline Remainder of series & 188 & 120 & 64 & 68 & 3 \\
\hline Whole series & 204 & 129 & 63 & 75 & 3 \\
\hline
\end{tabular}

per cent. showed no abnormality, while 18 per ce had narrowing of the disc space and 12 per cent. had arthritis. Of the 136 patients who never experienced cramp, 44 per cent. showed no abnorfaality, 17 per cent. had narrowing of the disc space, and 14 per cent. had arthritic lipping. The radidgraphs in the group developing cramp after opefstion and in the general series were taken at the time of the follow up, when arthritic changes, if an, would be at their maximum. The fact that the $x$-ray appearances of the lumbar spine in the cases developing cramp were roughly similar in type $a$ and frequency to those of the general series suggests that arthritis had little or no part in the ætiolog gf these cramps, while in the pre-operative group -it played no part whatever. Radiographs taken the time were little or no different from those taken before operation, the variation being no more then in the group not developing cramp.

Relationship of Cramp to Results of Operation. An investigation was made into whether patiengs who had cramp before operation did better or worge than those without cramp at that stage. Mogfe detailed results will be published later, and here the cases are merely divided into good and bad. TRe results are without significance. (Table VIII.)

TABLE IX

RELATIONSHIP OF CRAMP TO RESULTS OF OPERATION PATIENTS DEVELOPING CRAMP AFTER OPERATION

\begin{tabular}{|c|c|c|c|c|c|}
\hline \multirow[t]{2}{*}{ Cases with cramp } & \multirow{2}{*}{ No. } & \multicolumn{2}{|c|}{$\begin{array}{l}\text { Good } \\
\text { result }\end{array}$} & \multicolumn{2}{|c|}{$\begin{array}{l}\text { Bad } \\
\text { resulţ }\end{array}$} \\
\hline & & No. & $\%$ & No. & \\
\hline Onẹ or more root divided .. & 43 & 28 & 65 & 15 & 3ङ \\
\hline No root divided $\ldots$ & 9 & 5 & 56 & 4 & 49 \\
\hline Total with cramp & 52 & 33. & 64 & 19 & 3 营. \\
\hline Cases without cramp & 136 & 87 & 64 & 49 & 30 \\
\hline Whole series & 204 & 129 & 63 & 75 & 3 \\
\hline
\end{tabular}


TABLE X

OPERATIVE PROCEDURE ON SIXTEEN PATIENTS WITH CRAMP BEFORE OPERATION

\begin{tabular}{l|c|c|c|c}
\hline & $\begin{array}{c}\text { Disc } \\
\text { removal } \\
\text { only }\end{array}$ & $\begin{array}{c}\text { Disc } \\
\text { removal } \\
\text { and } \\
\text { posterior } \\
\text { root } \\
\text { section }\end{array}$ & $\begin{array}{c}\text { No disc } \\
\text { found ; } \\
\text { no } \\
\text { nerve } \\
\text { section }\end{array}$ & Total \\
\hline $\begin{array}{l}\text { No. of cases with } \\
\text { cramp before } \\
\text { operation only }\end{array}$ & 3 & 6 & 1 & 10 \\
\hline $\begin{array}{l}\text { No. of cases with } \\
\text { cramp before } \\
\text { a n d a f t e r } \\
\text { operation }\end{array}$ & 0 & 5 & 1 & 6 \\
\hline
\end{tabular}

The next point investigated was whether, in patients developing cramp after operation, the cramps occurred more commonly in the operative failures or in the successes. It will be seen that the results are approximately the same in the groups with and without cramp as compared with the whole series and therefore the appearance of cramp after operation has no prognostic significance. (Table,IX.)

Persistence of Cramp after Operation.-Of the sixteen patients with cramp before the operation, only six had it afterwards, the remaining ten being free. The operative procedures carried out on these patients were as given in Table X.

Cramp and Duration of Symptoms of Prolapsed Disc.-In order to see if there was any relationship between the occurrence of cramp and the length of history before operation, the average' duration of symptoms of prolapsed intervertebral disc for the various groups was compared with that of the

TABLE Xí

AVERAGE DURATION OF SYMPTOMS OF PROLAPSED DISC

\begin{tabular}{|c|c|c|}
\hline Series & $\begin{array}{l}\text { No. in } \\
\text { series }\end{array}$ & $\begin{array}{l}\text { Average duration } \\
\text { of symptoms } \\
\text { before operation }\end{array}$ \\
\hline Pre-operative cramps & 16 & 3 yrs. 5 mths. \\
\hline $\begin{array}{l}\text { Postoperative cramps : } \\
\text { with root section } \\
\text { without root section }\end{array}$ & $\begin{array}{r}43 \\
9\end{array}$ & $\begin{array}{l}4 \text { yrs. } 10 \text { mths. } \\
5 \text { yrs. } 9 \text { mths. }\end{array}$ \\
\hline Total & 52 & 4 yrs. 11 mths. \\
\hline $\begin{array}{l}\text { Cases without cramp pre- } \\
\text { or postoperative }\end{array}$ & 136 & 3 yrs. 9 mths. \\
\hline Whole series & 204 & 4 yrs. $1 \mathrm{mth}$. \\
\hline
\end{tabular}

whole series (Table XI). In the patients with cramp before operation the duration of symptoms was slightly less than in those without it, suggesting that there was no relationship. In contrast, the patients with cramp after operation had a much longer duration of symptoms before surgical treatment; this was especially so in the patients who had cramp without root section. The longer duration of symptoms suggests the possibility of more damage to nerve roots by prolapsed material, but whether this is the correct explanation is doubtful in view of the short histories in the patients with pre-operative cramp. It seems likely that the duration of stretching of nerve fibres by prolapsed material is only one factor, and possibly of less importance than the size and site of prolapse.

Cramp and Type of Symptoms.-All the 204 patients under review had sciatica, but there were five without any backache and eleven with slight pain in the back compared with that along the sciatic nerve distribution. Of these five without backache, two had cramps in the calf after operation. All the remaining patients had both backache and sciatica ; and, although it was difficult to estimate accurately, the impression was that there was little or no relationship between severity of sciatic pain and the occurrence of cramp. It may be argued that the occurrence of cramps after operation was more dependent on the severity of pain due to nerve root involvement than on root section, and that the latter procedure happened to be done only in the patients with severe pain. The longer duration of symptoms in the patients with cramp after operation is compatible with the greater nerve involvement in these cases. Often, however, the nerve was sectioned irrespective of the severity of pain, and sometimes this was done because of the small amount of prolapsed material removed. As these cases also developed cramp, the essential cause seems to be degenerative changes in the nerve root due to section or stretching by a prolapsed disc.

\section{Discussion}

From the results of this study, it seems that cramp is more likely to occur in cases of prolapsed intervertebral disc when there is involvement of the posterior nerve roots by prolapsed material as in large lateral protrusions. That cramp can occur as a result of posterior root irritation is well known and is an explanation of their frequency in such a condition as subarachnoid hæmorrhage. Gootnick (1943) believes that the cramps seen in arthritis of the hip or knee, in weak feet, or in intrinsic inflammatory changes in nerves, such as sciatica, are clonic contractions of a muscle group due to 
reflex bombardment of the myoneural junction by a stream of impulses from the neighbouring source of irritation, and he likens them to a variety of segmental visceromotor reflex, such as the abdominal rigidity in peritoneal inflammation. This theory would explain the occurrence of cramp in the pre-operative patients. In the postoperative patients the cramp seems to be related to posterior root division. Although posterior rhizotomy is an operation which has been practised for a long time for various painful conditions, no mention of the incidence of cramp after operation could be found on perusal of the literature. After division of the posterior nerve root three possible series of changes may occur: a peripheral, a central, and changes at the site of section. These will be considered in turn.

Dividing the posterior root should, theoretically, leave the dorsal root ganglion, its afferent sensory fibres, and their terminal sensory endings in muscle intact, all degeneration occurring proximal to the cut. If there are efferent autonomic fibres in the posterior root, after section it is possible that some peripheral degenerative changes may occur, affecting either the muscle fibres, the sensory endings, the myoneural junction, or the blood supply, and rendering the muscle fibres more liable to pass into spontaneous contraction. This might be transmitted to other fibres in the muscle until spasm resulted under various sets of conditions. The existence in man of sympathetic fibres in dorsal roots has not been proved, while the presence of parasympathetic fibres arising in the lateral horns of grey matter, and running to single end plates in muscle via dorsal root and ganglion (Kuré, 1931), is not universally accepted. Apart from these possibilities it is difficult to conceive how peripheral changes may occur by other known mechanisms, though their occurrence cannot be excluded. Dawson and Ladell, in a personal communication, stated that they found the cramp produced by acute salt deficiency was relieved by an intravenous injection of salt, except in a leg from which the circulation had been cut off by a pneumatic cuff. When circulatory arrest had abolished both the ankle jerk and the reflex responses to electrical stimulation, cramp no longer occurred, either during electrical stimulation or during voluntary contraction of the muscle. This suggests that an intact reflex arc is necessary for the objective and subjective phenomena of cramp to be present together. If this is true, the cramp in rhizotomy patients is dependent on intact reflex arcs in other segments of the cord. Unfortunately, there is no muscle which is innervated entirely by one segmental level of the cord, so it is not possible to prove whether such a muscle will go into cramp after division of is sensory root. The observations recorded in this paper suggest that there may be some correlation between nerve root divided and muscle affectes but there were exceptions, as was expected from the overlap between the segments and muscles inne? vated. Weddell (1945) has shown in the case of pain sensation in normal skin that there is a networ of nerve endings arranged so that any one area of skin is supplied by several overlapping terminats derived from different areas. In muscles the nerve terminals form a much looser meshwork, so the individual neural terminals in this meshwork a isolated from each other (Feindel, Weddell, and Sinclair, 1948). The utilization of intact refle arcs in cramp production might be possible wi this anatomical arrangement, while the reductiog in pattern of afferent impulses after rhizotomy might form a basis for explanation of the pain associated with these cramps, as has been postulatedy in the case of nerve nets and terminals subserving. cutaneous pain sensation when isolated from neighbours, instead of interweaving with them in normal skin (Weddell, Sinclair, and Feinder, 1948). The possibility that the painful elementoin? cramp is transmitted to the cord through infact posterior roots via sympathetic afferent sens $\overrightarrow{\text { ry }}$ fibres in these rhizotomy cases cannot be excluded.

The central changes would consist of degeneratian of the sensory fibres as they entered the cord as faif as the intercalatory neurone in the posterior lor or even to the anterior horn cell. Loss of trolling action of afferent impulses would have effect on these neurones and might cause them to send out impulses to the muscles, resulting in their spasm. The pain of the cramp would have to utilize intact sensory fibres at other levels described above. The posterior root degeneratiog could be compared with the pathological change occurring in tabes dorsalis. In this disease, over 90 per cent. of all cases experience lightning pain and " an abrupt reflex or half-conscious "start' of limb muscles may accompany the 'shoot' of 'the pain" (Wilson, 1940). The periodic occurrence of painful crises associated with spasm of smooth musc $\bar{E}$ also. demonstrates the motor accompaniment of changes in the posterior nerve roots. It seems more likely, therefore, that the motor component of these: cramps is dependent on central degenerative changes rather than hypothetical peripheral alterations.

The third factor to be considered is the change in the cut surface of the nerve root or in the cases witg pre-bperative cramp the site of impingement of prolapsed disc on nerve root. Granit and others (1944) showed that an " artificial synapse" could be formed in a mixed nerve either by sectioning 
or even ligating it without damaging it enough to stop normal distal conduction. This may be the mechanism of pain and cramp production in these cases, the affected nerve or the peripheral end of the sectioned posterior root acting as a short-circuiting point causing impulses to descend perhaps antidromally.

One point needing further explanation is why the cramps diminish with time. If they are due to changes in the muscle fibres or in sensory endings, are these changes reversible with the passage of time, or do other intact fibres take over their functional connexions? If the cramps are due to changes in the cord, is their gradual diminution due to completion of degenerative changes in the cut fibre and its connexions, or is it due to the time needed for other fibres and nerve endings in the cord to take over completely the functional connexions with released neurones? Such questions cannot be answered at present, and further speculation would be unprofitable. Thus, the observations made in this paper, though interesting, do not help in the elucidation of the problem of cramp. Nevertheless, if they are confirmed, they would have to be taken into account in any theory of the mechanism of cramp.

Quinine, which was suggested by Gootnick (1943) as being effective in cramp due to reflex irritation, was not tried in the present series. By the time these patients were seen the cramps had become infrequent, so that no therapy was necessary; even if quinine had been given, its efficacy would have been difficult to assess owing to the natural improvement that was taking place.

In one patient seen after this follow-up, in whom severe cramp was a prominent symptom and in whom it persisted after the response of the sciatica to conservative treatment, quinine was very effective. This patient later needed surgical treatment owing to the recurrence of sciatica.

\section{Summary and Conclusions}

1. The occurrence of cramp as a symptom in sciatica due to prolapsed intervertebral disc was

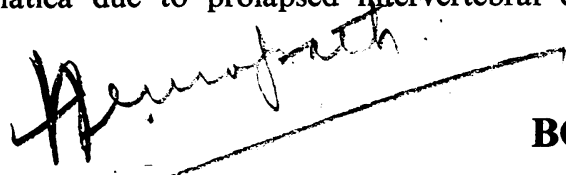

Observations on the Pathology of Hydrocephalus. By Dorothy S. Russell. 1949. M.R.C. Special Report. Series No. 265. London, H.M. Stationery Office. Pp. 138. Price 6s. net.

This monograph is the result of seventeen years of post-mortem study of hydrocephalus in the child and the adult. There are three possible causes for hydrocephalus : (1) excessive formation of the cerebrospinal fluid; (2) interference with the circulation of the fluid; studied in a series of 204 cases followed up one to seven years after operation.

2. The incidence of cramp was found to be higher after operation when, in addition to removal of the protruded disc material, a posterior nerve root has been cut.

3. The cramp occurring in these postoperative cases gradually diminished with time.

4. The significance of these findings is discussed in relation to the mechanism of cramp production.

5. The occurrence of cramp, whether before or after operation, is of no prognostic significance as regards the operative result.

6. While not helping in elucidating the mechanism of cramp, these findings, if confirmed, must be taken into account in any comprehensive theory of cramp.

My thanks are due to Mr. James Hardman, F.R.C.S., without whose work and original suggestion, this investigation would not have been undertaken.

This work was carried out by the author while holding the E. G. Fearnsides Research Scholarship, University of Cambridge.

\section{REFERENCES}

Bradford, F. K., and Spurling, R. G. (1941). "The Intervertebral Disc." First Edition. Charles C. Thomas, Springfield, Illinois. p. 74.

Feindel, W. H., Weddell, G., and Sinclair, D. C. (1948). J. Neurol. Neurosurg. Psychiat., 11, 113.

Gootnick, A. (1943). Arch. int. Med., 71, 555.

Granit, R., Leksell, L., and Skoglund, C. R. (1944). Brain, 67, 125.

Kuré, K. (1931). "Die vierfache Muskelinnervation einschliesslich der Pathogenese und Therapie der progressiven Muskeldystrophie." Urban and Schwarzenberg. Berlin.

Lenhard, R. E. (1947). 'J. Bone Jt. Surg., 29, 425.

O'Connell, J. E. A. (1943). Brit. J. Surg., 30, 315.

Pemberton, R. (1935). "Arthritis and Rheumatoid Conditions." Second Edition. Baillière, Tindall, and Cox, London. p. 51 .

Walker, E. (1945). South. med. J., 38, 832.

Weddell, G. (1945). British med. Bull., 3, 167.

- Sinclair, D. C., and Feindel, W. H. (1948). J. Neurophysiol., 11, 99.

Wilson, S. A. K. (1940). " "Neurology." Edward Arnold, London. p. 491. and (3) failure of adequate absorption of fluid into the blood and lymph channels. Recent work discounts the first possibility, as it seems unlikely that either hypertrophy of the choroid plexuses or increased capillary pressure in them, for example, as a result of thrombosis of their efferent veins, ever result in hydrocephalus. About the third possible cause there is no certain knowledge, but a number of clinical cases of dilatation of the ventricles, as a sequel to extensive sinus throm- 